\title{
MicroRNA-1294 inhibited oral squamous cell carcinoma growth by targeting c-Myc
}

\author{
ZUOJUN WANG ${ }^{1 *}$, JINSHENG YAN $^{2 *}$, TINGQIAN ZOU $^{1}$ and HUI GAO ${ }^{3}$ \\ ${ }^{1}$ Department of Stomatology, Stomatological Hospital of Jingmen City, Jingmen, Hubei 448000; \\ ${ }^{2}$ School of Traditional Chinese Medicine, Jinan University, Guangzhou, Guangdong 510632; \\ ${ }^{3}$ Department of Obstetrics and Gynecology, Union Hospital, Tongji Medical College, \\ Huazhong University of Science and Technology, Wuhan, Hubei 430022, P.R. China
}

Received December 15, 2017; Accepted May 22, 2018

DOI: $10.3892 / \mathrm{ol} .2018 .8967$

\begin{abstract}
Oral squamous cell carcinoma (OSCC) is the predominant histological type of oral cancer. The 5-year survival rate of OSCC is only $\sim 50 \%$. c-Myc is a known oncogene and target gene in various cancer types, including OSCC. The presnet study revealed that c-Myc is one of the target genes of miR-1294. Results indicated lower levels of miR-1294 in OSCC tissues samples collected from 24 patients with OSCC. Notably, overexpression of miR-1294 inhibited proliferation and migration in OSCC cell lines and inhibition of miR-1294 promoted cell growth and migration in OSCC cell lines. Moreover, miR-1294 can target the 3'UTR of c-Myc, as we identified a negative correlation between c-Myc mRNA expression and miR-1294 expression in 24 OSCC tissues. In conclusion, the data demonstrate the tumor suppressive role of miR-1294 in OSCC.
\end{abstract}

\section{Introduction}

Oral squamous cell carcinoma (OSCC) is the predominant histological types of oral cancer (1). Alcohol drinking, tobacco smoking, bad oral hygiene, and human papilloma virus infections are the main risk factors of $\operatorname{OSCC}(2,3)$. In China, there were 34.319 new cases diagnosed as oral cavity cancer in 2010, including 23,096 males and 11,223 females (4).

Correspondence to: Dr Tingqian Zou, Department of Stomatology, Stomatological Hospital of Jingmen City, 19 Changning Avenue, Dongbao, Jingmen, Hubei 448000, P.R. China

E-mail: wangzuojun24680@126.com

Dr Hui Gao, Department of Obstetrics and Gynecology, Union Hospital, Tongji Medical College, Huazhong University of Science and Technology, 1095 Jiefang Avenue, Wuhan, Hubei 430022, P.R. China

E-mail: ghde915@126.com

*Contributed equally

Key words: miR-1294, OSCC, c-Myc, cell growth
Early detection oral of cancer is currently challenging because although conventional oral examination can detect tumors located in the oral cavity from the early stages, it fails to identify all oral premalignant lesions (5).

Surgery is the primary therapy for oral cancer, especially for patients in advanced stages. Chemotherapy and radiation therapy are often combined with surgery in treating patients with advanced oral cancer. Nevertheless, the 5-year survival rate of patients with OSCC is only $~ 50 \%$ (6). Therefore, the mechanism underlying of OSCC development should be elucidated, to optimize treatment and improve patient survival.

c-Myc is a known oncogene, as well as target gene, in various types of cancers, including lung (7-10) and breast cancer (10-12), and hepatocellular carcinoma $(13,14)$. Previous studies showed that the c-Myc protein was overexpressed in $80 \%$ of the OSCC (15), Genome-wide profiling of OSCC has also shown that, among other genes, gain of c-Myc gene occurred at a high frequency (16).

In the present study, we investigated the function of miR-1294 in OSCC, and tried to provide a potential therapeutic target of OSCC.

\section{Materials and methods}

Tissues samples. For the present study, 24 OSCC tissues samples and their matched adjacent normal tissues were acquired from the Department of Stomatology, Stomatological Hospital of Jingmen City, Hubei Province, China. The pathological diagnosis of all OSCC patients was confirmed by the senior pathologists of the Stomatological Hospital of Jingmen City. Tissues were frozen immediately, and preserved in a $-80^{\circ} \mathrm{C}$ freezer for further analysis, including the detection of miR-1294 and c-Myc mRNA. Written informed consent was obtained from all patients, and the present study was approved by the Ethics Committees of the Stomatological Hospital of Jingmen City.

HE staining. The 24 OSCC tissues was processed in standard protocol for hematoxylin and eosin (HE) staining. Briefly, $4-\mu \mathrm{m}$ thick sections were cut. After deparaffinization (dunk for $45 \mathrm{sec}$ in xylene) and hydration (dunk for $45 \mathrm{sec}$ in propanol), the slides were staining in hematoxylin for 3-5 $\mathrm{min}$, 
and washed in running water for $5 \mathrm{~min}$. After differentiated in $1 \%$ acid alcohol $(30 \mathrm{sec})$, the slides were staining in $1 \%$ eosin $\mathrm{Y}$ for $10 \mathrm{~min}$. Then, these slides were dehydrated in increasing concentration of alcohol (each for $5 \mathrm{~min}$ ) and clear in xylene for observation. These slides were observed optical microscope (CX23; Olympus, Shinjuku, Tokyo, Japan).

Cell culture. Overall, 4 OSCC cell lines (HSC2, HSC4, SAS and KON) were acquired from the Cell Bank of the Chinese Academy of Medical Sciences. The 4 OSCC cell lines were cultured in Dulbecco's modified Eagles medium F-12 HAM (Sigma-Aldrich; Merck KGaA, Darmstadt, Germany) with $10 \%$ fetal bovine serum (FBS; Gibco; Thermo Fisher Scientific, Inc., Waltham, MA, USA). Primary gingival keratinocytes (PGK; ATCC ${ }^{\circledR}$ PCS-200-014 ${ }^{\mathrm{TM}}$ ) were purchased from American Type Culture Collection (ATCC; Manassas, VA, USA) and cultured in Dermal Cell Basal Medium (ATCC ${ }^{\circledR}$ PCS-200-030 ${ }^{\mathrm{TM}}$ ) plus one Keratinocyte Growth Kit (ATCC ${ }^{\circledR}$ PCS-200-040

Detection of miR-1294 in OSCC tissue samples and SAS cells. The levels of miR-1294 in the 24 OSCC tissues cells and HSC2, HSC4, SAS and KON cells were detected by qRT-PCR. In detail, the total RNA was extracted from the 24 specimens using the TRIzol reagent, according to the manufacturers's protocol (Invitrogen; Thermo Fisher Scientific, Inc., Waltham, MA, USA). The level of miR-1294 was then detected by TaqMan miRNA RT Real-Time PCR (17). Single-stranded cDNA was synthesized by the TaqMan MicroRNA Reverse Transcription Kit (Applied Biosystems; Thermo Fisher Scientific, Inc., Waltham, MA, USA), and then amplified by TaqMan Universal PCR Master Mix (Invitrogen; Thermo Fisher Scientific, Inc.) and miRNA-specific TaqMan MGB probes (Applied Biosystems).The U6 snRNA was used for normalization (18). The c-Myc mRNA levels in the OSCC tissues were assayed by real-time qPCR (delta $\mathrm{Cq}$ method of quantification) using the SYBR-Green reagent (Shanghai Shengong Biotechnology Co., Ltd., Shanghai, China) $(19,20)$. The primers used for c-Myc (human) are listed as follows: F, 5'-AATGAAAAGGCCCCCAAGGTAGTTATCC-3 and R, 5'-GTCGTTTCCGCAACAAGTCCTCTTC-3; GAPDH F, 5'-CTGACTTCAACAGCGACACC-3' and R, 5'-TAGCCA AATTCGTTGTCATACC-3'. The following thermocycling conditions were maintained: $94^{\circ} \mathrm{C}$ for $5 \mathrm{~min} ; 30$ cycles of $94^{\circ} \mathrm{C}$ for $45 \mathrm{sec}, 55^{\circ} \mathrm{C}$ for $45 \mathrm{sec}$ and $72^{\circ} \mathrm{C}$ for $1 \mathrm{~min}$; and $72^{\circ} \mathrm{C}$ for $10 \min (21)$.

Overexpression and downregulation of miR-1294 in SAS cells. miR-1294 was overexpressed by miR-1294 mimics and decreased by miR-1294 antisense oligonucleotides (ASO), as described in a previous study (18). miR-1294 mimics, miR-1294 ASO and control miRNA were purchased from Shanghai Shengong Biotechnology Co., Ltd. miRNAs were transfected into cells using the Lipofectamine ${ }^{\circledR} 2000$ reagent (Thermo Fisher Scientific, Inc.).

Cell proliferation assay. Cellular growth was analyzed by the MTT assay, as previously described (22-25). Briefly, SAS cells were cultured in 96-flat well plates overnight, at a cells density of $5 \times 10^{5} /$ well. The MTT reagent $(0.1 \mathrm{mg} / \mathrm{ml})$ was added into the medium for $5 \mathrm{~min}$, followed by the addition of $100 \mu \mathrm{l}$ of DMSO. The optical density (OD) value was measured on a microplate reader, with a $570 \mathrm{~nm}$ filter.

Cell migration assay. Transwell systems were used to assess cell migration. In detail, the Transwell chambers $(8.0 \mu \mathrm{m}$ pore; Sigma-Aldrich; Merck KGaA) were placed in 24-well plates. The miR-1294 mimics or ASO-transfected SAS cells were FBS deprived for $12 \mathrm{~h}$, and subsequently added to the upper chambers. Medium containing $10 \%$ FBS was placed in the lower chambers and, after $24 \mathrm{~h}$, the migrating SAS cells were counted.

Prediction of the putative targets of miR-1294. The putative targets of miR-1294 were predicted by the online software Targetscan (http://www.targetscan.org/vert_71/). TargetScan predicts biological targets of miRNAs by searching for the presence of $8 \mathrm{mer}, 7 \mathrm{mer}$, and 6 mer sites that match the seed region of each miRNA (26).

Dual luciferase reporter assays. SAS cells were seeded at $1 \times 10^{5}$ cells/well and were serum-starved for $6 \mathrm{~h}$ pre-transfection. Mutants of c-Myc 3' untranslated region (3'UTR) were generated using the Site-Directed Mutagenesis Kit (Huijun Company, China). The 3'UTR of c-Myc and mutated controls were cloned and inserted into the reporter plasmid (500 ng) (Promega Corporation, Madison, WI, USA). miR-1294 mimics were then transfected into the SAS cells containing either the wild-type or mutant 3'UTR plasmids, using Lipofectamine 2000 (Invitrogen; Thermo Fisher Scientific, Inc.). Twenty-four hours later, cells were harvested and the luciferase activity was measured using the Dual-Luciferase Reporter Assay System (Huijun Company).

Plasmid transfection. c-Myc overexpression plasmid (pcDNA3.1-c-Myc) was constructed by Sangon Biotech Co., Ltd. (Shanghai, China. Then, miR-1294 mimics and pcDNA3.1-c-Myc plasmid were co-transfected into SAS cells, using Lipofectamine 2000 (Invitrogen; Thermo Fisher Scientific, Inc.). In details, cells should be $70-90 \%$ confluent at the time of transfection. Diluted DNA and diluted Lipofectamine 2000 were mixed gently and incubated for $20 \mathrm{~min}$ at room temperature. Then, the $100 \mu \mathrm{l}$ of complexes were added into each well containing cells and medium. Then, incubated SAS cells at at $37^{\circ} \mathrm{C}$ in a $\mathrm{CO}_{2}$ incubator for $18-48 \mathrm{~h}$ prior to testing for transgene expression.

Western blot analysis. SAS Cells were thawed and lysed in lysis buffer $(150 \mathrm{mM} \mathrm{NaCl}, 50 \mathrm{mM}$ Tris-HCI, $1 \%$ Triton X-100 and $0.1 \%$ SDS) with the Protease Inhibitor Cocktail (Sigma-Aldrich; Merck KGaA) and the Phosphatase Inhibitor Cocktail (Sigma-Aldrich; Merck KGaA). Protein was separated by $10 \%$ SDS-PAGE gel and was transferred into PVDF membrane. Then, the membrane was blocked in $5 \%$ bovine serum albumin (BSA; A1933; Sigma-Aldrich; Merck KGaA) for $1 \mathrm{~h}$. For c-Myc analysis, an anti-c-Myc antibody (ab11917; Abcam, Cambridge, UK) was prepared in 5\% BSA (1:500). The membrane was incubated with c-Myc antibody in $4^{\circ} \mathrm{C}$ for overnight. After washed by 3 times, the membrane was incubated with a peroxidase-linked antibody to rabbit antibody IgG 
A
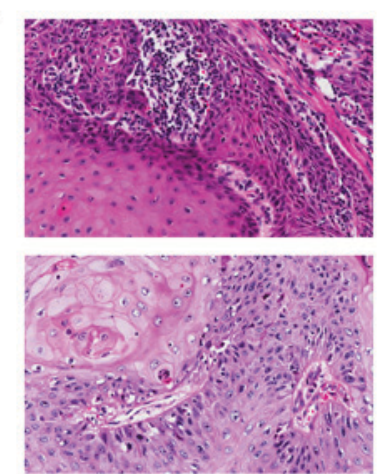

B
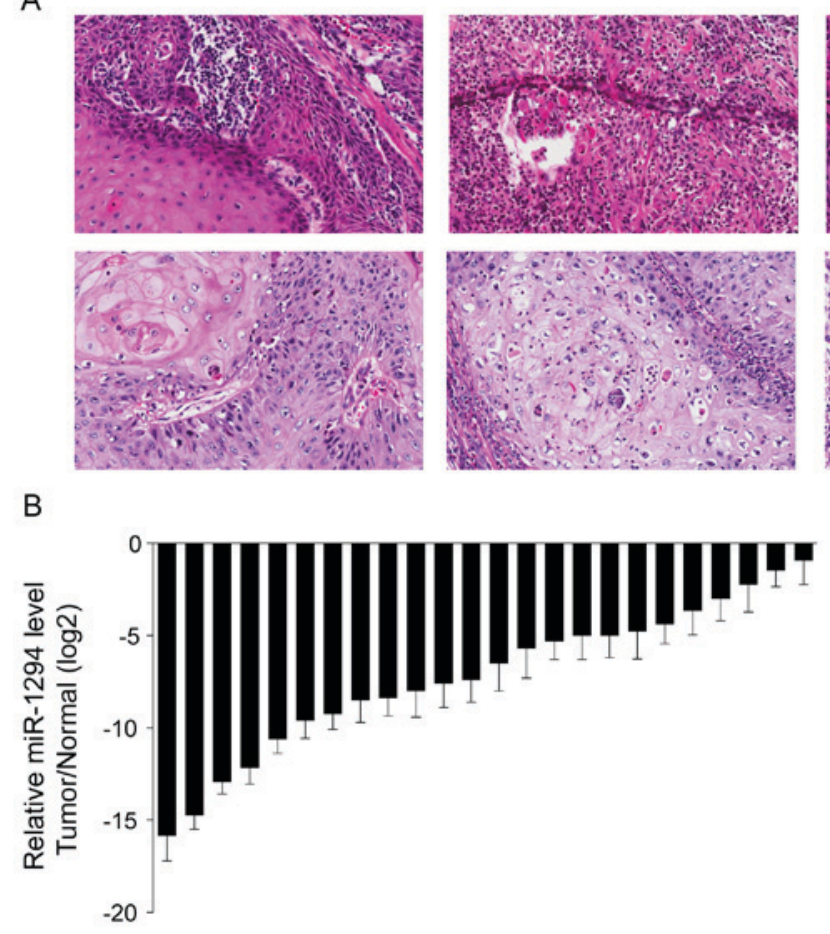

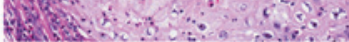

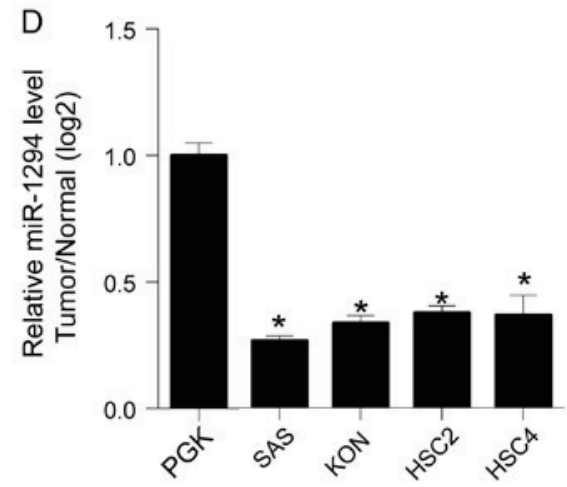

$\times 200$
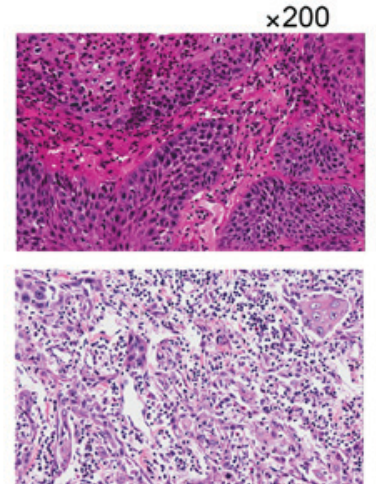

C

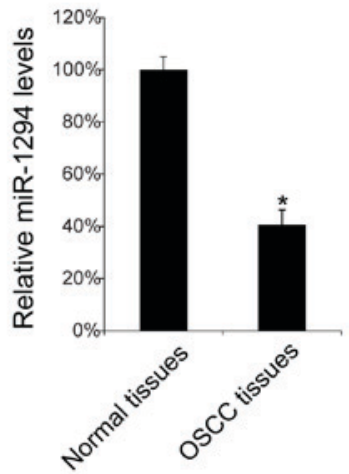

Figure 1. Relatively low level of miR-1294 in OSCC tissue samples. (A) The representative image of OSCC tissues HE staining (magnification, x200). The miR-1294 levels of 24 OSCC tissues samples and their matched adjacent normal tissues were assessed by qRT-PCR. Relative miR-1294 levels tumor/normal $(\log 2)$ were listed (B); the mean miR-1294 values of the OSCC tissues and their matched adjacent normal tissues were also recorded. (C) ${ }^{*} \mathrm{P}<0.05$ vs. Normal tissues. (D) The miR-545 levels of 5 OSCC cell lines (HSC2, HSC4, SAS and KON) and primary gingival keratinocytes (PGK) were assayed by qRT-PCR. ${ }^{*} \mathrm{P}<0.05$ vs. PGK. These experiments were performed in triplicate. OSCC, oral squamous cell carcinoma.

(ab218695; 1:2,000 dilution; Abcam) in room temperature for 2 h. Proteins were detected with the ECL Western Blotting Detection Reagents (GE Healthcare, Chicago, IL, USA). Images were analyzed using Image J [National Institutes of Health (NIH) Bethesda, MD, USA, USA]. $\beta$-actin was used as an internal control. For $\beta$-actin detection, an anti- $\beta$-actin antibody (ab8226; Abcam) was prepared in 5\% BSA $(1: 2,000)$. The following steps were same with the steps of detecting c-Myc.

Statistical analysis. All experiments were repeated 3 times. Data are shown as mean \pm SD. Two-tailed Student's t-test was used to analyze the mean value between two groups; one-way ANOVA was used to test the mean value among 3 groups or more with post hoc contrasts by Student-Newman-Keuls test. The correlation between c-Myc and miR-1294 levels were tested by Pearson correlation coefficient analysis. The indicator of statistical significance was $\mathrm{P}<0.05$. All calculations were performed using the SPSS software (version 16.0) (SPSS, Inc., Chicago, IL, USA).

\section{Results}

miR-1294 levels in OSCC tissues. Initially, the 6 preventatives image of OSCC tissues are shown (Fig. 1A). The expression levels of miR-1294 in 24 OSCC tissues and their matched adjacent normal tissues were analyzed by qRT-PCR. Results indicated lower levels of miR-1294 in OSCC tissues (Fig. 1B). This was reflected by the mean value of miR-1294 in the 24 OSCC tissues, which was lower than the mean value in the 24 normal adjacent tissues (Fig. 1C). Then, we assayed the miR-1294 levels in normal primary gingival keratinocytes and 4 OSCC cell lines (HSC2, HSC4, SAS and KON), and found that SAS cells showed the lowest levels of miR-1294 (Fig. 1D). 

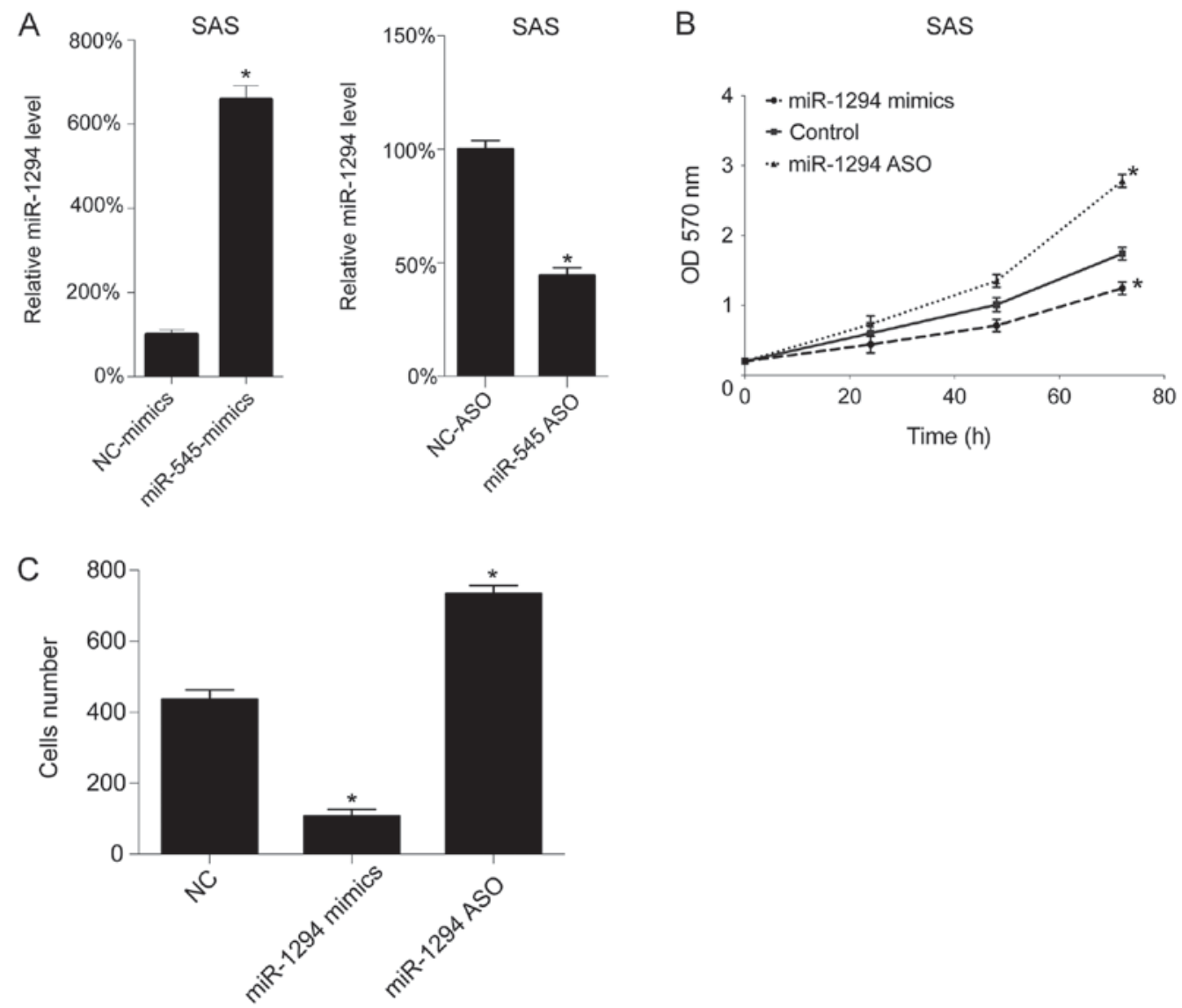

Figure 2. Overexpression of miR-1294 inhibited the proliferation and migration of SAS and vice versa. miR-1294 was overexpressed by miR-1294 mimics transfection, and downregulated by miR-1294 antisense oligonucleotides (ASO) transfection in SAS cells. miR-1294 levels were assayed by qRT-PCR, $24 \mathrm{~h}$ post-transfection. "P<0.05 vs. NC-mimics or NC-ASO (A). The cellular proliferation of SAS cells, following transfection, was assayed by MTT analysis. ${ }^{*} \mathrm{P}<0.05$ vs. Control (B). To assess cellular migration, SAS cells were added to the upper chamber with a non-coated membrane in each group, respectively. After $6 \mathrm{~h}$, the cells in the lower chamber were counted. "P $<0.05$ vs. NC (C). These experiments were performed in triplicate.

In vitro role of miR-1294 in SAS cells. Next, we assessed the function of miR-1294 in vitro. The levels of miR-1294 levels were upregulated and downregulated by miR-1294 mimics and miR-1294 ASO transfection, respectively. As expected, miR-1294 mimics transfection increased the level of miR-1294 in SAS cells, whereas miR-1294 ASO transfection decreased the level of miR-1294 in the SAS cells (Fig. 2A). Next, cell growth following transfection was assessed using by MTT assay. As seen in Fig. 2B, upregulation of miR-1294 inhibited cell growth, whereas downregulation promoted cell growth in SAS cells. Subsequently, we analyzed cell migration following transfection, and found that miR-1294 mimics decreased the number of migrating cells, whereas miR-1294 ASO increased the number of migrating cells, in SAS cells (Fig. 2C).

c-Myc is a target gene of miR-1294. Next we attempted to determine that whether c-Myc is a target gene of miR-1294. c-Myc is a very important oncogene, which shows a high amplification mutation across all various types of tumors (Fig. 3A). The potential binding sites of the 3'UTR of c-Myc were revealed by bioinformatics methods (Fig. 3B). To establish whether miR-1294 could target c-Myc, mutants of 3'UTR of c-Myc were generated and, subsequently transfected into luciferase reporter plasmids. miR-1294 mimics and c-Myc mutants were co-transfected into SAS cells. At $24 \mathrm{~h}$ post-transfection, that miR-1294 mimics reduced the luciferase activity of the 3'UTR of wild-type c-Myc, but not that of mutated of 3'UTR of c-Myc (Fig. 3C). Forty-eight hours later, the c-Myc protein levels were determined by western blot analysis. As shown in Fig. 3D, miR-1294 mimics inhibited the expression of c-Myc in SAS cells (Fig. 3D). Moreover, we assayed the c-Myc mRNA expression levels in the 24 OSCC tissues, and correlated c-Myc mRNA expression with miR-1294 expression. Obtained results revealed a negative correlation between c-Myc mRNA expression and miR-1294 expression in the 24 OSCC tissue samples (Fig. 3E).

$c-M y c$ reduces the inhibitory effect of $m i R-1294$. To confirm miR-1294 play its role via c-Myc, we performed the rescue experiment including plasmid transfection and cell migration assay. We overexpressed the c-Myc levels in SAS cells by c-Myc overexpression plasmid transfection (pcDNA3.1c-Myc). Twenty-four hours later, the c-Myc mRNA levels in SAS cells was analyzed by qRT-PCR, and we found that pcDNA3.1-c-Myc increased the c-Myc levels in SAS cells (Fig. 4A). Next miR-1294 mimics and pcDNA3.1-c-Myc plasmid were co-transfected into SAS cells, then the cells growth were tested by MTT analyzed, and we found that miR-1294 inhibited cells growth as expected, and c-Myc overexpression plasmid restored the inhibitory effect of 


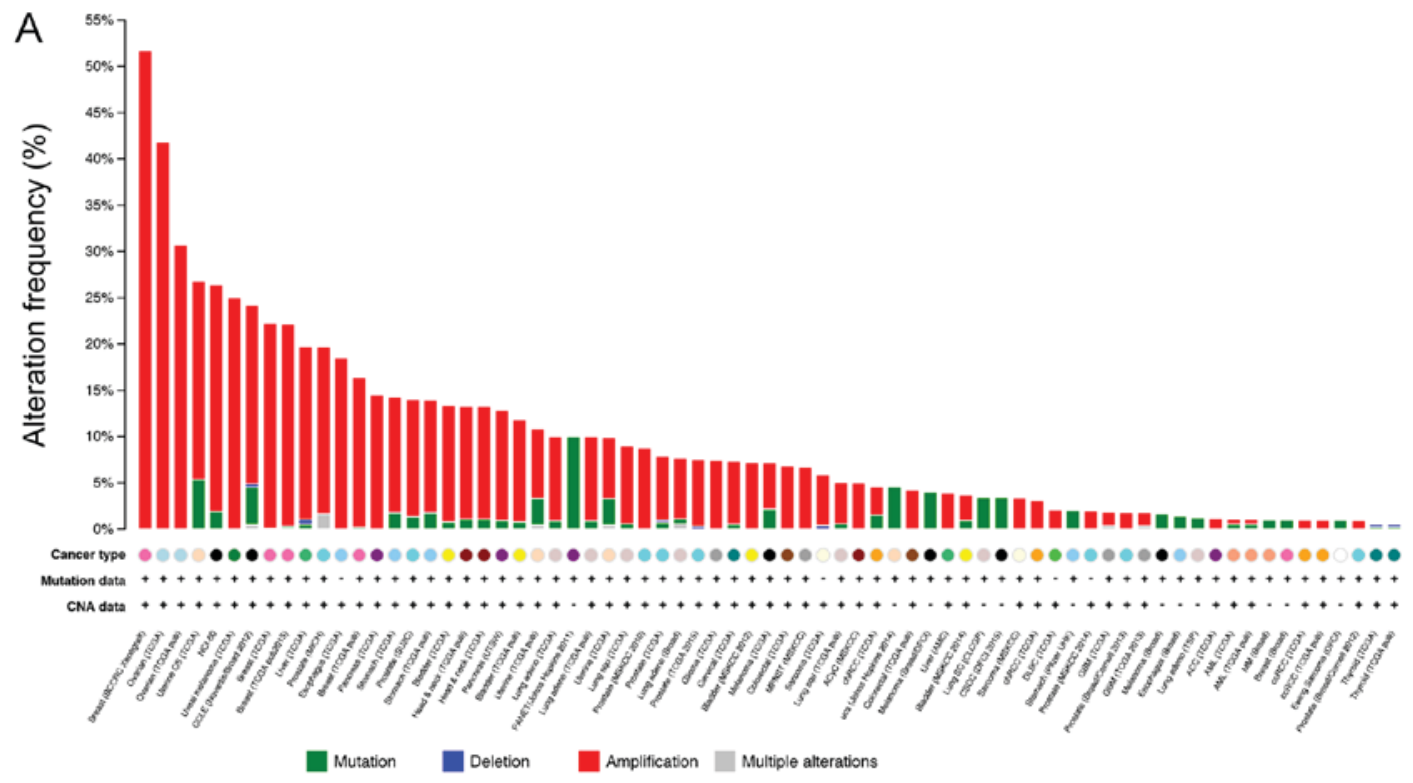

B

Position 86-93 of MYC 3' UTR

hsa-miR-1294

5' ...GCAUGaUCAAAUGCA-ACCUCACA.....

3' UCUGUUGUUACGGUUGGAGUGU

Position $86-93$ of MYC 3' UTR

$5^{\prime}$

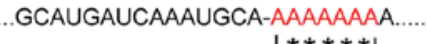

hsa-miR-1294

3' UCUGUUGUUACGGUUGGAGUGU

C

MYC 3'UTR
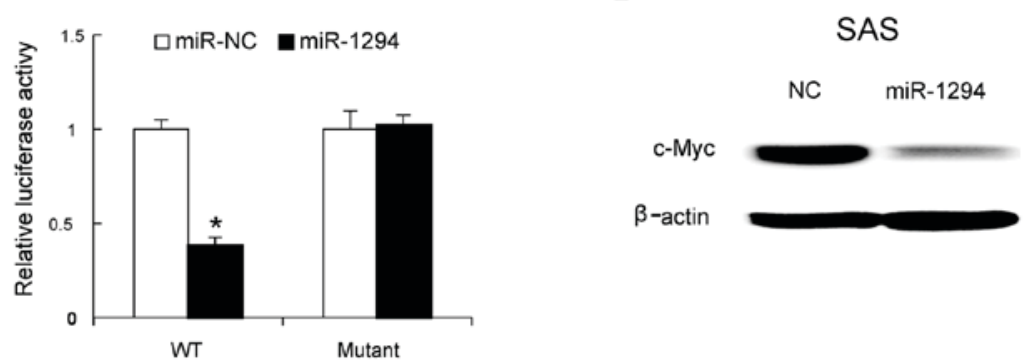

E

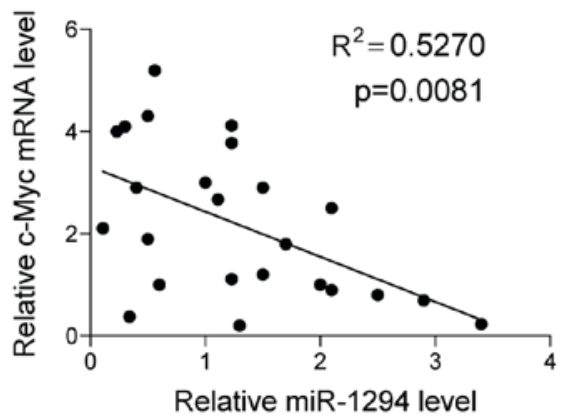

Figure 3. c-Myc is targeted by miR-1294. (A) C-Myc amplification mutation across all various types of tumors. (B) The binding sites and the location of the two mutations were listed. miR-1294 mimics and a plasmid containing either wild-type or mutated 3'UTR sequence of c-Myc were transfected into SAS cells and, after $48 \mathrm{~h}$, the luciferase activity was analyzed. (C) "P<0.05 vs. miR-NC. (D) The amount of c-Myc protein in SAS cells was determined post-transfection by western blotting. (E) The correlation between miR-1294 and c-Myc was analyzed by Pearson correlation coefficient analysis. Each experiment was repeated at least 3 times.

miR-1294 (Fig. 4B). Subsequently, we analyzed cell migration following transfection, and found that miR-1294 mimics decreased the number of migrating cell, whereas c-Myc overexpression plasmid restored the inhibitory effect of miR-1294, in SAS cells (Fig. 4C).
TRL4, TLR6, TLR8 and TLR9 are target genes of miR-1294. TLR2, TLR4 and TLR9 were expressed in primary tumors, neck metastases as well as in recurrent tumors of OSCC. We found that miR-1294 could target TRL4, TLR6, TLR8 and TLR9 (Fig. 5). 

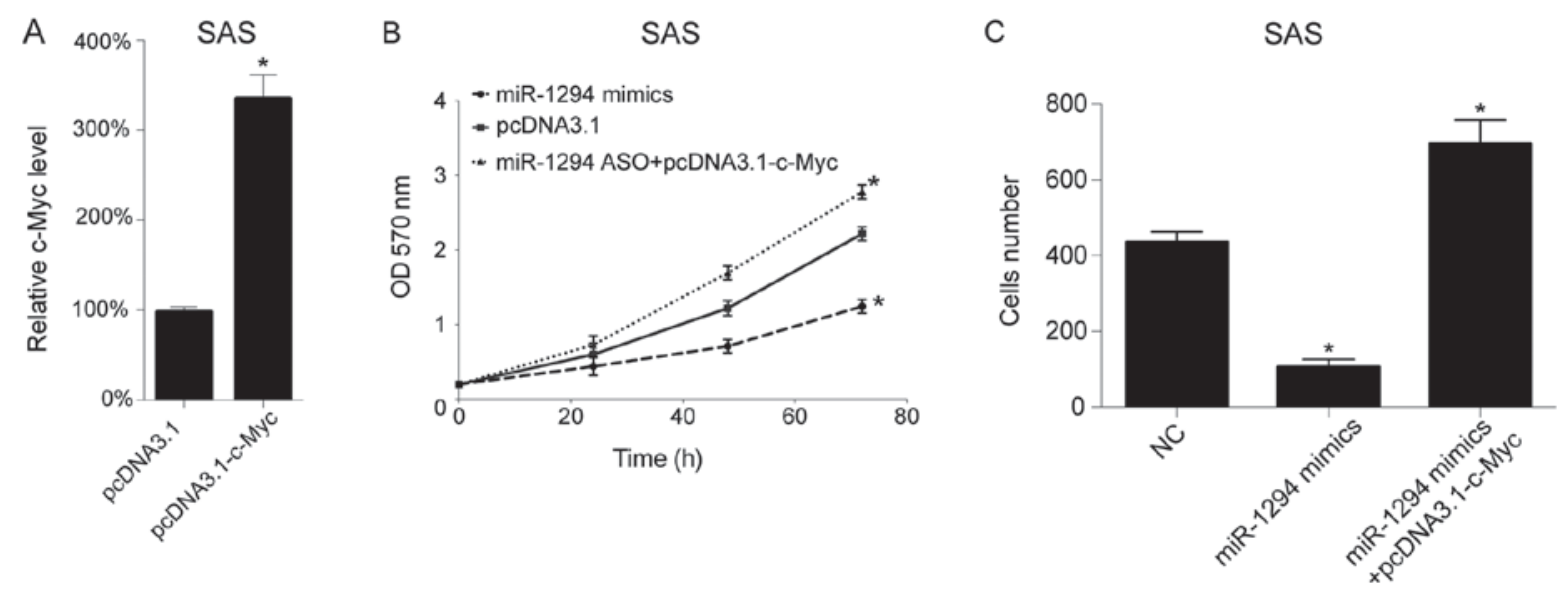

Figure 4. c-Myc overexpression plasmid restored the inhibitory effect of miR-1294. pcDNA3.1-c-Myc plasmid was transfected into SAS cells, empty plasmid was used as a control. Twenty-four hours later, the c-Myc mRNA levels in SAS cells was analyzed by qRT-PCR. The c-Myc mRNA in control group was arbitrarily defined as $100 \%$. (A) "P<0.05 vs. pcDNA3.1. pcDNA3.1-c-Myc plasmid and miR-1294 mimics were co-transfected into SAS cells, cell proliferation was tested by MTT assay following transfection. (B) "P<0.05 vs. pcDNA3.1. pcDNA3.1-c-Myc plasmid and miR-1294 mimics were co-transfected into SAS cells, and were placed into the upper chamber with a non-coated membrane in each group, respectively. (C) After $6 \mathrm{~h}$, the cells in the lower chamber were counted. ${ }^{*} \mathrm{P}<0.05$ vs. NC. Each experiment was repeated at least 3 times.

\begin{tabular}{|c|c|}
\hline $\begin{array}{l}\text { Position } 4505-4511 \text { of TLR4 3' UTR } \\
\text { hsa-miR-1294 }\end{array}$ & $\begin{array}{r}5^{\prime} \quad \ldots \text { AUACCUUGUUGGCAGACCUCACU. } \\
\text { I I I I I I I I } \\
\text { 3' UCUGUUGUUACGGUUGGAGUGU }\end{array}$ \\
\hline $\begin{array}{c}\text { Position } 2686-2692 \text { of TLR6 3' UTR } \\
\text { hsa-miR-1294 }\end{array}$ & $\begin{array}{r}5^{\prime} \quad . . \text { AGUGGAAAGUAGGUUCCUCACAG } \\
\text { I I I I I I I I I } \\
\text { 3' UCUGUUGUUACGGUUGGAGUGU }\end{array}$ \\
\hline $\begin{array}{c}\text { Position 2658-2664 of TLR8 3' UTR } \\
\text { hsa-miR-1294 }\end{array}$ & 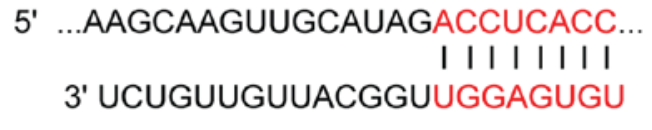 \\
\hline Position 40-46 of TLR9 3' UTR & $\begin{array}{r}5^{\prime} \ldots \text {...GCCACCUCCACACUCACCUCACC... } \\
1111111 \\
3^{\prime} \quad \text { UCUGUUGUUACGGUUGGGUGU }\end{array}$ \\
\hline
\end{tabular}

Figure 5. Binding sites of miR-1294 between TLR4, TLR6, TLR8 and TLR9.

\section{Discussion}

In the present study, the function of miR-1294 in OSCC was investigated. Our data showed that miR-1294 levels in OSCC tissues were lower than the levels in matched adjacent normal tissues. Overexpression of miR-1294 inhibited the proliferation and migration of SAS cells, and vice versa. To the best of our knowledge, this is the first report on the inhibitory function of miR-1294 in OSCC. In esophageal squamous cell carcinoma, inhibitory effect of miR-1294 on the translation of c-Myc has been already described and proved by Liu et al (18). Our study showed the similar scenario as this previous study described and stress the function of miR-1294 in OSCC.

The role of c-Myc has been intensively studied in head and neck cancers including OSCC. In OSCC, c-Myc level was overexpressed (27), more importantly, overexpression of c-Myc is correlated with poor prognosis of OSCC (28). The underlying mechanism is that c-Myc is elicited mainly via activation of transcription of those c-Myc target genes that are positive regulators of the cell cycle, such as cyclins D1, D2, E and A,
Cdk4, e2f1, e2f2, Cdc25A and B (29,30). Thus it is possible that the low levels of miR-1294 may be also correlated with poor prognosis of OSCC. However, whether c-Myc and miR-1294 are correlated with the grade of pathology, whether c-Myc play a role in cell migration are unclearly. In further study, we will investigated these issues and analyze c-Myc protein in tissues by western blotting and immunohistochemical. The correlation of the expression of miR-1294 and the grade of pathology may be tested and the morphology of migrated cells will be observed by microscope. We will collect more OSCC specimen and analyzed this possibility in a further study.

Bioinformatics methods predicted that TRL4, TLR6, TLR8 and TLR9 are target genes of miR-1294 (Fig. 5). Toll-like receptors (TLRs) are cell surface or intracellular transmembrane proteins, acting as pattern-recognition receptor. TLRs are capable of recognizing bacterial, viral, fungal and protozoal components (31-38). A previous study showed that TLR2, TLR4 and TLR9 were expressed in primary tumors, neck metastases as well as in recurrent tumors of OSCC (39). As OSCC developed in an immune cell-rich environment, 
immune cells interact with cancer cells intensively, resulting in a network of regulation. For example, TLR2 played a role in Treg expansion and their suppressive capacity (40). Thus, we guessed that TRL4, TLR6, TLR8 and TLR9 maybe be involved in the regulation of immune microenvironments of OSCC, and miR-1294 may play its antitumor role partly by targeting Toll-like receptors.

In conclusion, our data reveal the inhibitory role of miR-1294 in OSCC.

\section{Acknowledgements}

The authors would like to thank Dr Zhumei Wu (Department of Stomatology, Stomatological hospital of Jingmen City, China) for the helpful discussion.

\section{Funding}

This work was supported by Funding of Hubei Province (grant no. 020716040026).

\section{Availability of data and materials}

All data generated or analyzed during this study are included in this published article.

\section{Author's contributions}

ZW and JY collected patient data and performed cell experiments. JY and TZ performed PCR, western blotting and other molecular experiment. HG contributed to study design and manuscript writing.

\section{Ethics approval and consent to participate}

The present study was approved by Ethic Committee of Tongji Medical College, Huazhong University of Science and Technology and each patient provided written informed consent.

\section{Consent for publication}

All patients gave informed consent for the use of their tissues and publication of the data and images.

\section{Competing interests}

The authors declare that they have no competing interests.

\section{References}

1. Rivera C: Essentials of oral cancer. Int J Clin Exp Pathol 8: 11884-11894, 2015.

2. Gupta PC: Mouth cancer in India: A new epidemic? J Indian Med Assoc 97: 370-373, 1999.

3. Mehrotra R, Singh M, Kumar D, Pandey A, Gupta R and Sinha U: Age specific incidence rate and pathological spectrum of oral cancer in Allahabad. Indian J Med Sci 57: 400-404, 2003.

4. Zheng CM, Ge MH, Zhang SS, Tan Z, Wang P, Zheng RS, Chen WQ and Xia QM: Oral cavity cancer incidence and mortality in China, 2010. J Cancer Res Ther 11 (Suppl 2): C149-C154, 2015.
5. Lingen MW, Kalmar JR, Karrison T and Speight PM: Critical evaluation of diagnostic aids for the detection of oral cancer. Oral Oncol 44: 10-22, 2008.

6. Ries L, Eisner M, Kosary C, et al (eds): Cancer statistics review, 1975-2002. Bethesda, MD: National Cancer Institute 21, 2005.

7. Little CD, Nau MM, Carney DN, Gazdar AF and Minna JD Amplification and expression of the c-myc oncogene in human lung cancer cell lines. Nature 306: 194-196, 1983.

8. Yanaihara N, Caplen N, Bowman E, Seike M, Kumamoto K, Yi M, Stephens RM, Okamoto A, Yokota J, Tanaka T, et al: Unique microRNA molecular profiles in lung cancer diagnosis and prognosis. Cancer Cell 9: 189-198, 2006.

9. Engelman JA, Zejnullahu K, Mitsudomi T, Song Y, Hyland C Park JO, Lindeman N, Gale CM, Zhao X, Christensen J, et al: MET amplification leads to gefitinib resistance in lung cancer by activating ERBB3 signaling. Science 316: 1039-1043, 2007.

10. Dubik D, Dembinski TC and Shiu RP: Stimulation of c-myc oncogene expression associated with estrogen-induced proliferation of human breast cancer cells. Cancer Res 47: 6517-6521, 1987.

11. Chen CR, Kang Y and Massagué J: Defective repression of c-myc in breast cancer cells: A loss at the core of the transforming growth factor beta growth arrest program. Proc Natl Acad Sci USA 98: 992-999, 2001.

12. Escot C, Theillet C, Lidereau R, Spyratos F, Champeme MH, Gest $\mathrm{J}$ and Callahan R: Genetic alteration of the c-myc protooncogene (MYC) in human primary breast carcinomas. Proc Natl Acad Sci USA 83: 4834-4838, 1986.

13. Peng SY, Lai PL and Hsu HC: Amplification of the c-myc gene in human hepatocellular carcinoma: Biologic significance. J Formos Med Assoc 92: 866-870, 1993.

14. Hsu T, Möröy T, Etiemble J, Louise A, Trépo C, Tiollais P and Buendia MA: Activation of c-myc by woodchuck hepatitis virus insertion in hepatocellular carcinoma. Cell 55: 627-635, 1988.

15. Pai R, Pai S, Lalitha R, Kumaraswamy S, Lalitha N, Johnston R and Bhargava M: Over-expression of c-Myc oncoprotein in oral squamous cell carcinoma in the South Indian population. Ecancermedicalscience 3: 128, 2009.

16. Chen YJ, Lin SC, Kao T, Chang CS, Hong PS, Shieh TM and Chang KW: Genome-wide profiling of oral squamous cell carcinoma. J Pathol 204: 326-332, 2004.

17. Schmittgen TD, Lee EJ, Jiang J, Sarkar A, Yang L, Elton TS and Chen C: Real-time PCR quantification of precursor and mature microRNA. Methods 44: 31-38, 2008.

18. Liu K, Li L, Rusidanmu A, Wang Y and Lv X: Down-regulation of miR-1294 is related to dismal prognosis of patients with esophageal squamous cell carcinoma through elevating c-Myc expression. Cell Physiol Biochem 36: 100-110, 2015.

19. Bustin SA: Quantification of mRNA using real-time reverse transcription PCR (RT-PCR): TRends and problems. J Mol Endocrinol 29: 23-39, 2002.

20. Livak KJ and Schmittgen TD: Analysis of relative gene expression data using real-time quantitative PCR and the $2^{-\Delta \Delta C_{\mathrm{T}}}$ method. Methods 25: 402-408, 2001.

21. Ren X, Zhang Z, Tian J, Wang H, Song G, Guo Q, Tian J, Han Y, Liao Q, Liu G, et al: The downregulation of c-Myc and its target gene hTERT is associated with the antiproliferative effects of baicalin on HL-60 cells. Oncol Lett 14: 6833-6840, 2017.

22. Gerlier D and Thomasset N: Use of MTT colorimetric assay to measure cell activation. J Immunol Methods 94: 57-63, 1986.

23. Fotakis $\mathrm{G}$ and Timbrell JA: In vitro cytotoxicity assays: Comparison of LDH, neutral red, MTT and protein assay in hepatoma cell lines following exposure to cadmium chloride. Toxicol Lett 160: 171-177, 2006.

24. Twentyman PR and Luscombe M: A study of some variables in a tetrazolium dye (MTT) based assay for cell growth and chemosensitivity. Br J Cancer 56: 279-285, 1987.

25. Ferrari M, Fornasiero MC and Isetta AM: MTT colorimetric assay for testing macrophage cytotoxic activity in vitro. J Immunol Methods 131: 165-172, 1990.

26. Lewis BP, Burge CB and Bartel DP: Conserved seed pairing, often flanked by adenosines, indicates that thousands of human genes are microRNA targets. Cell 120: 15-20, 2005.

27. Field J: Oncogenes and tumour-suppressor genes in squamous cell carcinoma of the head and neck. Eur J Cancer B Oral Oncol 28: 67-76, 1992.

28. Field JK, Spandidos DA, Stell PM, Vaughan ED, Evan GI and Moore JP: Elevated expression of the c-myc oncoprotein correlates with poor prognosis in head and neck squamous cell carcinoma. Oncogene 4: 1463-1468, 1989. 
29. de Nigris F, Sica V, Herrmann J, Condorelli G, Chade AR, Tajana G, Lerman A, Lerman LO and Napoli C: c-Myc oncoprotein: cell cycle-related events and new therapeutic challenges in cancer and cardiovascular diseases. Cell Cycle 2: 325-328, 2003.

30. Dang CV: c-Myc target genes involved in cell growth, apoptosis, and metabolism. Mol Cell Biol 19: 1-11, 1999.

31. Takeda K, Kaisho T and Akira S: Toll-like receptors. Annu Rev Immunol 21: 335-376, 2003.

32. Moresco EM, LaVine D and Beutler B: Toll-like receptors. Curr Biol 21: R488-R493, 2011.

33. Akira S, Takeda K and Kaisho T: Toll-like receptors: Critical proteins linking innate and acquired immunity. Nat Immunol 2: 675-680, 2001

34. Fig TLR: Toll-like receptors, 2017.

35. Aderem A and Ulevitch RJ: Toll-like receptors in the induction of the innate immune response. Nature 406: 782-787, 2000.

36. Kawai T and Akira S: The role of pattern-recognition receptors in innate immunity: Update on Toll-like receptors. Nat Immunol 11: 373-384, 2010.

37. Takeda $\mathrm{K}$ and Akira S: Toll-like receptors in innate immunity. Int Immunol 17: 1-14, 2005.
38. Kawai T and Akira S: Toll-like receptors and their crosstalk with other innate receptors in infection and immunity. Immunity 34 : 637-650, 2011.

39. Mäkinen LK, Ahmed A, Hagström J, Lehtonen S, Mäkitie AA, Salo T, Haglund C and Atula T: Toll-like receptors 2, 4, and 9 in primary, metastasized, and recurrent oral tongue squamous cell carcinomas. J Oral Pathol Med 45: 338-345, 2016.

40. Sutmuller RP, den Brok MH, Kramer M, Bennink EJ, Toonen LW, Kullberg BJ, Joosten LA, Akira S, Netea MG and Adema GJ: Toll-like receptor 2 controls expansion and function of regulatory T cells. J Clin Invest 116: 485-494, 2006.

This work is licensed under a Creative Commons Attribution-NonCommercial-NoDerivatives 4.0 International (CC BY-NC-ND 4.0) License. 